\title{
IMPROVED FIELD ORIENTED CONTROL FOR STAND ALONE DUAL STAR INDUCTION GENERATOR USED IN WIND ENERGY CONVERSION
}

\author{
Yacine Bendjeddou $^{1 *}$ - Rachid Abdessemed ${ }^{1}$ - Elkheir Merabet ${ }^{1}$ \\ ${ }^{1}$ Laboratoire d'Electrotechnique de Batna LEB, Department of Electrical Engineering, Faculty of Technology, \\ University of Mustafa Benboulaid Batna-2, Street Chahid Mohamed El hadi Boukhlouf, 05000 Batna, Algeria
}

\begin{tabular}{l} 
ARTICLE INFO \\
\hline Article history: \\
Received: 20. 3. 2018. \\
Received in revised form: 20. 6. 2018. \\
Accepted: 26. 6. 2018. \\
\hline Keywords: \\
Self-excited dual star induction generator \\
Vector control \\
Fuzzy logic controller \\
PWM rectifiers \\
Magnetizing current and magnetizing inductance \\
estimation
\end{tabular}

DOI: http://doi.org/10.30765/er.40.2.05

\section{Introduction}

The first record of a multiphase motor drive known to the authors, dates back to 1969 when a five-phase voltage source inverter fed induction motor drive was proposed. During the next 20 years, the multiphase motor drives have attracted a steady, but rather limited attention [1].

At present, the application area of multiphase induction machine is more and more abroad due to its advantage. First, there is a reduction in the harmonic torque pulsations at a high frequency and in rotor harmonic currents. This minimizes rotor losses and the phase current in the machine and inverter without increasing the phase voltage. Other potential advantages are their high reliability and the possibility to divide the controller power on more inverter legs [2-10].

Some of the most suitable applications are the high current ones: ship propulsion, locomotive traction, electric vehicles, and aircraft [11-12]. Improved reliability is advantageous in nuclear power for its

\begin{abstract}
:
This paper presents a novel direct rotor flux oriented control with online estimation of magnetizing current and magnetizing inductance applied to self-excited dual star induction generator equipping a wind turbine in remote sites. The induction generator is connected to nonlinear load through two PWM rectifiers. The fuzzy logic controller is used to ensure the DC bus voltage a constant value when changes in speed and load conditions. In this study, a performance comparison between the conventional approach and the novel approach is made. The proposed control strategy is validated by simulation in Matlab/Simulink.
\end{abstract}

circulation pumps and for other similar application in process industries [3, 11].

A very interesting and discussed multiphase solution is a dual-stator induction machine (DSIM) that has two sets of three-phase windings spatially shifted by 30 electrical degrees with isolated neutral points.

Modeling, control, and performance of the dual star induction machine has been extensively covered in [2, 6, 3-17]

This paper investigates a control system for double star induction generator that uses a rotor flux orientation. A systematic analysis of this control system is carried out for wide ranges of both load and speed. The double star induction generator supplies a variable dc load. The main goal is to remain constant both rotor flux and DC voltage.

The introduction of the magnetization curve in the model of self-excited induction generator is very important for the operation of the generator. If we consider the magnetizing inductance constant, the model of the generator generates a tension which tends towards the infinite. This is why the

\footnotetext{
* Corresponding author. Tel.: +213667371133

E-mail address: yacineunivers@yahoo.fr
} 
introduction of a magnetizing inductance estimator is in the proposed control algorithm [18-24].

The direct rotor flux oriented control is favorable because of its simple structure and excellent decoupling characteristics. This is when the DC voltage and currents are accurately measured. The performance of this technical method depends on the constant of the rotor; this constant depends mainly on the saturation of the magnetic circuit of the generator [18].

Lots of works have been done in the literature using the rotor vector orientation control; the estimator of magnetizing inductance has not been included for improving accuracy in calculating the rotor flux position. They regulate DC voltage poorly, especially at low speeds or major changes of load. The magnetizing inductance is usually considered constant [19-21]. However, even in induction machines with a maximal variation of speed rotor, considering them as a constant, can lead to serious errors in the estimation of the time constant $[18,22-$ 24]. So, a similar effect can be expected in the dual star induction generator field oriented control systems as well.

The authors propose an improving self-induction generator vector control in which the estimator of magnetizing inductance is introduced; they estimated it by the relationship between the current in $\mathrm{d}$ axes and the inductance magnetizing. The magnetizing curve has been included in the proposed control system to more accurately calculate the rotor flux position. However, this approach required a current sensor, which complicated the control system [23]. In another approach proposed [22], a relationship between current reference in $\mathrm{d}-\mathrm{q}$ axes, the magnetizing current, and magnetizing inductance was found. This approach is very complicated but it doesn't require a current sensor.

In this paper, a new algorithm of control are introduced; an estimator of inductance magnetizing is introduced to vector control, contrary to the traditional algorithm where the inductance magnetizing is considered constant. A comparison of the two control systems has been presented. A fuzzy PI controller is proposed for optimization of DSIG's vector control. The proposed scheme is to some extent similar to that in [25], which makes the control system more robust.

\section{Modeling of self-excited dual star induction generator}

The model of a dual star induction generator is the same as the dual star induction motor. The PARK model of the dual star induction generator in the reference frame at the rotating field $(\mathrm{d}, \mathrm{q})$ is represented in Fig. 1.

The DSIG is composed of a stator having two identical phase winding offset by an electrical angle $\alpha=30^{\circ}$, and a squirrel cage rotor [25-27].

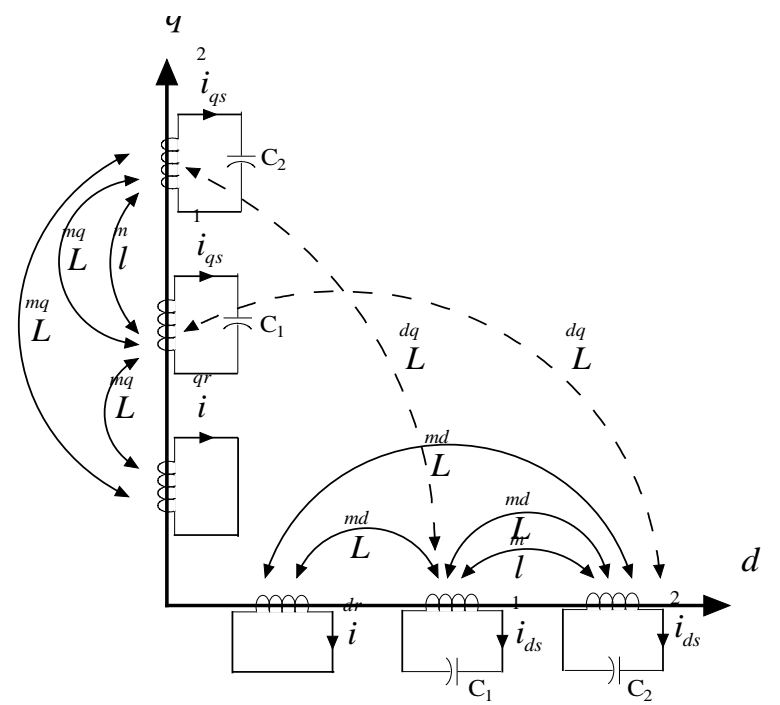

Figure 1. Representation of DSIG in the Park frame

The electrical equations of the dual stator winding induction generator in the synchronous reference frame (d-q) are given as [25-27]:

$$
\begin{gathered}
v_{d s 1}=-r_{1} i_{d s 1}-\omega_{e} \psi_{q s 1}+p \psi_{d s 1} \\
v_{q s 1}=-r_{1} i_{q s 1}-\omega_{e} \psi_{d s 1}+p \psi_{q s 1} \\
v_{q s 1}=-r_{1} i_{q s 1}-\omega_{e} \psi_{d s 1}+p \psi_{q s 1} \\
v_{q s 2}=-r_{2} i_{q s 2}-\omega_{e} \psi_{d s 2}+p \psi_{q s 2} \\
v_{d r}=0=r_{r} i_{d r}-\left(\omega_{e}-\omega_{r}\right) \psi_{q r}+p \psi_{d r} \\
v_{q r}=0=r_{r} i_{q r}+\left(\omega_{e}-\omega_{r}\right) \psi_{d r}+p \psi_{q r}
\end{gathered}
$$

$v_{d s 1}, v_{q s 1}, i_{d s 1}, i_{q s 1}, \psi_{d s 1}$ and $\psi_{q s 1}$ are respectively the ' $d$ ' and ' $q$ ' components of the first star voltages, currents and flux linkage. $v_{d s 2}, v_{q s 2}, i_{d s 2}, i_{q s 2}$, $\psi_{d s 2}$ and $\psi_{q s 2}$ are respectively the 'd' and ' $\mathrm{q}$ ' components of the second star voltages, currents, and flux linkage. 
$v_{d r}, v_{q r}, i_{d r}, i_{q r}, \psi_{d r}$ and $\psi_{q r}$ are respectively the ' $d$ ' and ' $q$ ' components of the rotor voltages, currents, and flux linkage. $r_{1}, r_{2}$ and $r_{r}$ are respectively the phase stator resistances for two star and rotor resistance.

$\omega_{e}$ is the speed of the synchronous reference frame; $\omega_{r}$ is the rotor electrical angular speed.

The expressions for the stator and rotor flux linkages are [24-29]:

$$
\begin{aligned}
& \psi_{d s 1}=-L_{l 1} i_{d s 1}-L_{l m}\left(i_{d s 1}+i_{d s 2}\right)-L_{d q} i_{q s 2} \\
& +L_{m d}\left(-i_{d s 1}-i_{d s 2}+i_{d r}\right) \\
& \psi_{q s 1}=-L_{l 1} i_{q s 1}-L_{l m}\left(i_{q s 1}+i_{q s 2}\right)-L_{d q} i_{d s 2} \\
& +L_{m q}\left(-i_{q s 1}-i_{q s 2}+i_{q r}\right) \\
& \psi_{d s 2}=-L_{l 2} i_{d s 2}-L_{l m}\left(i_{d s 1}+i_{d s 2}\right)-L_{d q} i_{q s 1} \\
& +L_{m d}\left(-i_{d s 1}-i_{d s 2}+i_{d r}\right) \\
& \psi_{q s 2}=-L_{l 2} i_{q s 2}-L_{l m}\left(i_{q s 1}+i_{q s 2}\right)-L_{d q} i_{d s 1} \\
& +L_{m q}\left(-i_{q s 1}-i_{q s 2}+i_{q r}\right) \\
& \psi_{d r}=-L_{l r} i_{d r}+L_{m d}\left(-i_{d s 1}-i_{d s 2}+i_{d r}\right) \\
& \psi_{q r}=-L_{l r} i_{q r}+L_{m q}\left(-i_{d s 1}-i_{d s 2}+i_{q r}\right)
\end{aligned}
$$

Where: $L_{m d}$ and $L_{m q}$ are respectively the direct and the quadrature magnetizing inductance.

$L_{s 1 d}=L_{l 1}+L_{m d}, L_{s 1 q}=L_{l 1}+L_{m q}, L_{s 2 d}=L_{l 2}+L_{m d}$,

$L_{s 2 q}=L_{l 2}+L_{m q}, L_{r d}=L_{l r}+L_{m d}, L_{r q}=L_{l r}+L_{m q}$

$L_{s 1 d}, L_{s 1 q}, L_{s 2 d}, L_{s 2 q}, L_{r d}$ and $L_{r q}$ are respectively the direct and quadrature of the stator and rotor inductances. The electromagnetic torque is evaluated as:

$$
\begin{aligned}
& T_{e m}=p \frac{L_{m}}{L_{l r}+L_{m}}\left[\left(i_{q s 1}+i_{q s 2}\right) \psi_{d r}-\right. \\
& \left.\left(i_{d s 1}+i_{d s 2}\right) \psi_{q r}\right]
\end{aligned}
$$

Where: $L_{m}$ is the magnetizing inductance.

The magnitude of the magnetizing current $\left|i_{m}\right|$ is calculated as:

$$
i_{m}=\sqrt{\left(-i_{d s 1}-i_{d s 2}+i_{d r}\right)^{2}+\left(-i_{q s 1}-i_{q s 2}+i_{q r}\right)^{2}}
$$

It must be emphasized that the generator needs residual magnetism so that the self-excitation process can be started. The magnetizing inductance, $L_{m}$ used in this work is given as follows [30]:

$$
\begin{aligned}
& L_{m}=0.1406 i_{m}+0.0014 i_{m} \\
& -0.0012 i_{m}{ }^{2}+0.00005 i_{m} 3
\end{aligned}
$$

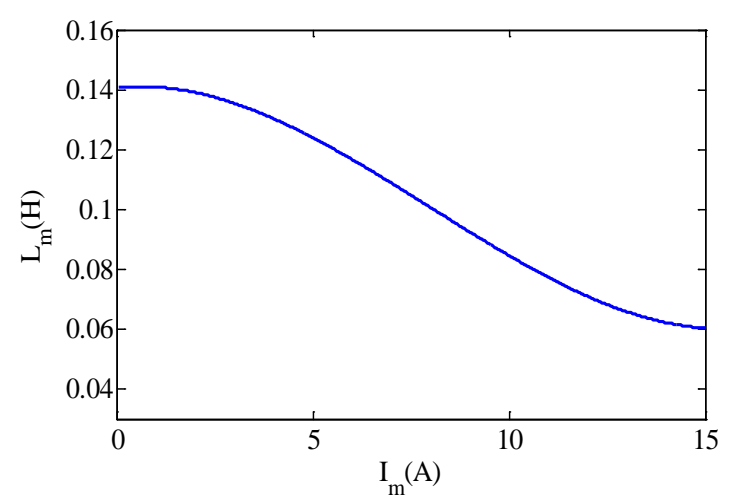

Figure 2. Variation of magnetizing inductance with magnetizing current

\section{Vector control}

The goal in the controlling system is to ensure DC bus voltage to its reference. This is obtained by controlling the flux and the power transmitted by the generator.

The objective of the direct field oriented control theory applied to the DSIG is, as in DC machine, to independently control the torque and the flux. In ideal field oriented control, the rotor flux linkage axis is forced to align with the d-axis and it follows that:

$$
\begin{gathered}
\psi_{d r}=\psi_{r}^{*} \\
p \psi_{d r}=\psi_{q r}=0
\end{gathered}
$$

Substituting (16)-(17) into (5)-(6), yields

$$
\begin{gathered}
r_{r} i_{d r}+p \psi_{r}^{*}=0 \longrightarrow i_{d r}=0 \\
r_{r} i_{d r}+p \psi_{r}^{*}=0 \longrightarrow i_{q r}=-\frac{\omega_{s l}^{*} \psi_{r}^{*}}{r_{r}}
\end{gathered}
$$

Where $\omega_{s l}^{*}=\omega_{e}^{*}-\omega_{r}, \omega_{s l}$ is the slip speed.

The rotor currents in terms of the stator currents are divided from (11) and (12) as:

$$
i_{d r}=\frac{1}{\left(L_{m}+L_{l r}\right)}\left[\psi_{r}^{*}-L_{m}\left(i_{d s 1}+i_{d s 2}\right)\right]
$$




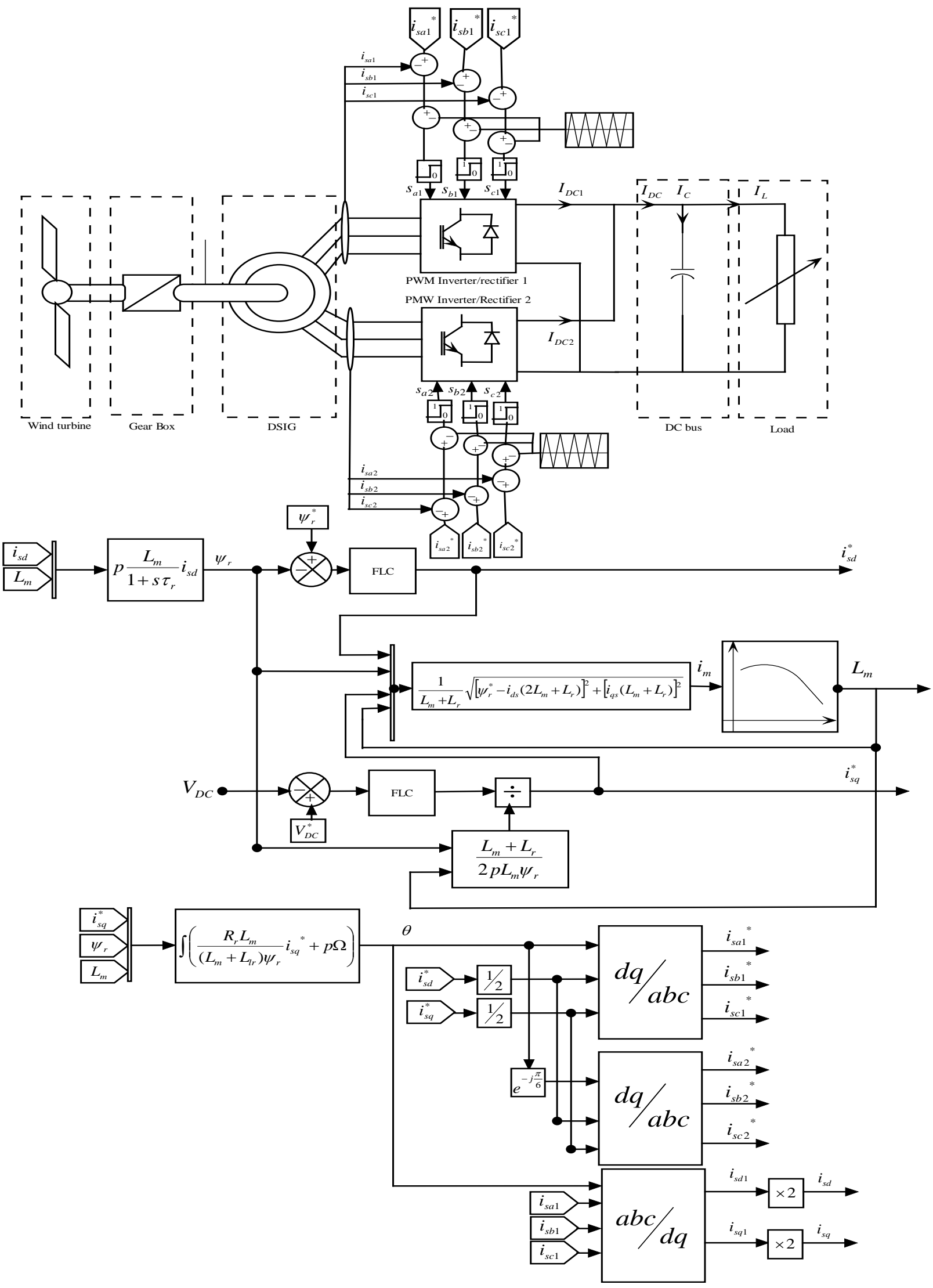

Figure 3. The algorithm of control 


$$
i_{q r}=-\frac{1}{\left(L_{m}+L_{l r}\right)}\left(i_{q s 1}+i_{q s 2}\right)
$$

Substituting (20) into (18), obtain

$$
\omega_{s l}^{*}=\frac{r_{r} L_{m}}{\left(L_{m}+L_{l r}\right) \psi_{r}{ }^{*}} i_{q s}^{*}
$$

Where:

$$
i_{q s 1}{ }^{*}+i_{q s 2}{ }^{*}=i_{q s}{ }^{*}
$$

From the desired value of the DC voltage, it is possible to express that the reference power by:

$$
V_{D C}{ }^{*} i_{d c}=P^{*}=P_{\text {ele }}=T_{e m} \Omega
$$

Neglecting the losses, the torque expression can be written as:

$$
T_{e m}=\frac{P^{*}}{\Omega}
$$

The component references of the stator current and slip speed $\omega_{s l}$ can be expressed as:

$$
i_{q s 1}{ }^{*}=\frac{\left(L_{l r}+L_{m}\right)}{p L_{m} \psi_{r}{ }^{*}} T_{e m}{ }^{*}
$$

The flux controlled by $i_{d s}$

$$
\psi_{r}=p \frac{L_{m}}{1+s \tau_{r}} i_{d s}
$$

Where:

$$
\begin{gathered}
i_{s d 1}+i_{s d 2}=i_{d s} \\
\tau_{r}=\frac{L_{r}}{r_{r}}
\end{gathered}
$$

The implementation of the control is presented in Fig. 3.

\subsection{Estimation of magnetizing inductance}

The magnetizing inductance depends on the magnetizing current amplitude $\left|I_{m}\right|$. Therefore, mainly if the generator is to operate in the flux weakening range, it is necessary to online estimate the $L_{m}$ value during operation.
By substituting expression (20)-(21) to (14), after simplification, we have the flowing expression:

$$
i_{m}=\frac{1}{L_{m}+L_{l r}} \sqrt{\begin{array}{l}
{\left[\psi_{r}^{*}-i_{d s}\left(2 L_{m}+L_{l r}\right)\right]^{2}} \\
+\left[i_{q s}\left(L_{m}+L_{l r}\right)\right]^{2}
\end{array}}
$$

The magnetizing inductance can be found as shown in Fig. 4:

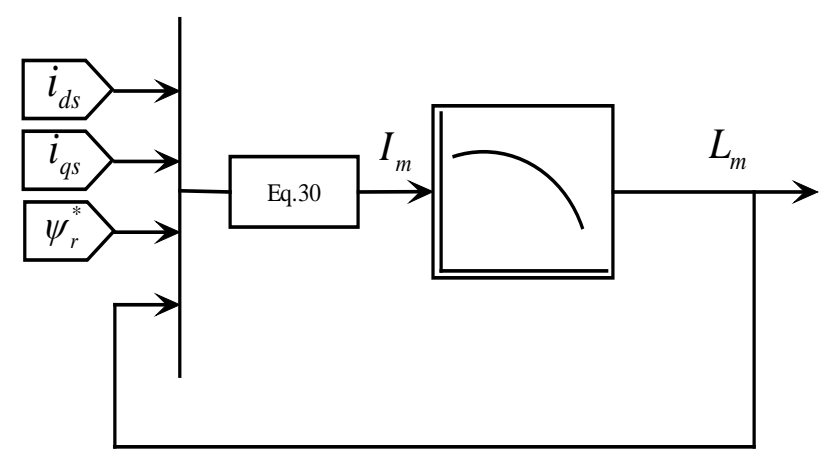

Figure 4. Magnetizing inductance estimation scheme

\section{The PWM current controller}

The problem of the varying switching frequency of the hysteresis current control can also be solved with a ramp comparison current controller. Here three current controllers produce the voltage commands, which are compared with the triangular carrier signal in a sinusoidal PWM manner. Because the PI controllers operate on AC signals inherent amplitude and phase error occur between the sinusoidal reference and the actual current.

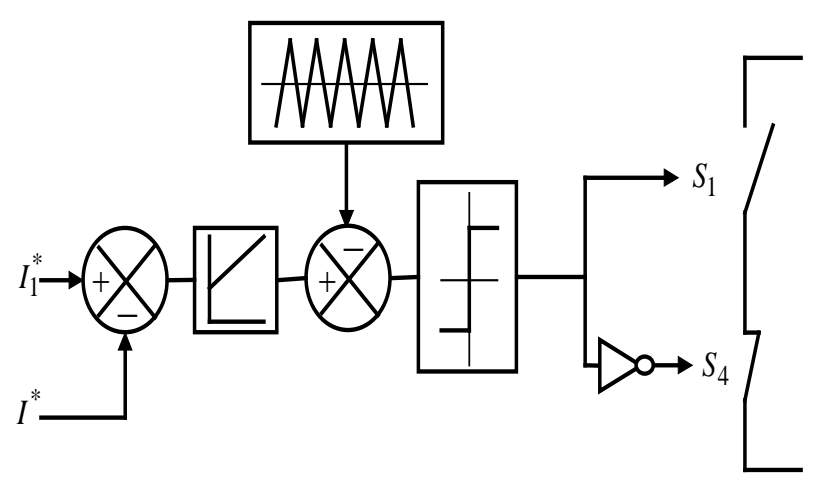

Figure 5. The PWM current control 


\section{The PI Controller}

\subsection{The DC bus voltage controller}

The corrector PI provided for DC bus voltage is written:

$$
i_{s q}^{*}=\left(k_{p D C}+\frac{k_{i D C}}{s}\right)\left(V_{D C}^{*}-V_{D C}\right)
$$

The $V_{D C}$ control scheme is shown in the following figure.

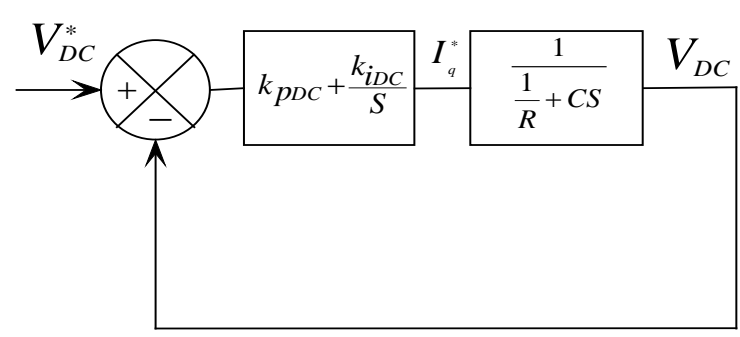

Figure 6. Closed-loop control of DC voltage

The system closed-loop transfer function is written:

$$
\begin{aligned}
& \frac{V_{D C}}{V_{D C}^{*}}=\frac{K_{p D C} s+K_{i D C}}{C s^{2}+K_{p D C} s+K_{i D C}} \\
& \frac{V_{D C}}{V_{D C}^{*}}=\frac{\tau s+1}{\frac{\tau C}{K_{p D C}} s^{2}+\tau s+1}
\end{aligned}
$$

Where: $\tau=\frac{K_{p D C}}{K_{i D C}}$

By identification with the canonical form:

$$
\frac{1}{\omega_{n}^{2}} s^{2}+\frac{2 \zeta}{\omega_{n}} s+1
$$

We obtained:

$$
\begin{gathered}
K_{p D C}=\frac{6 \zeta C}{t_{r}} \\
K_{i D C}=\frac{9 C}{t_{r}^{2}}
\end{gathered}
$$

We choose the coefficient for $\zeta=0.7, \omega_{n}=\frac{3}{t_{r}}$ and $t_{r}=10^{-1} s$

\subsection{The flux controller}

We consider an integral proportional corrector (PI) according to:

$$
i_{s d}^{*}=\left(k_{p \psi}+\frac{k_{i \psi}}{s}\right)\left(\psi_{r}^{*}-\psi_{r}\right)
$$

$k_{p \psi}$ : Proportional gain and $k_{i \psi}$ : integral gain, are the parameters of the corrector to be determined and $s$ is the Laplace operator.

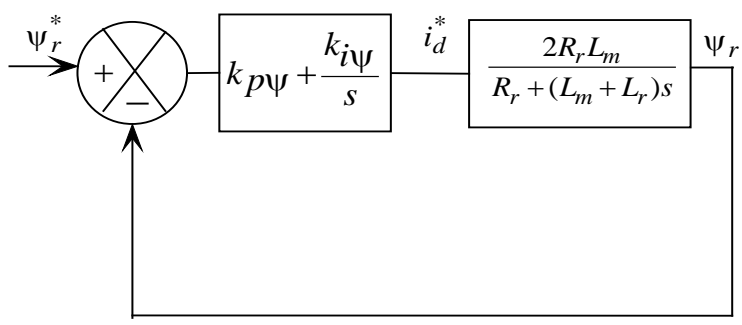

Figure 7. Closed-loop control of flux.

The system closed-loop transfer function is written:

$$
\begin{aligned}
& \frac{\psi_{r}}{\psi_{r}^{*}}= \\
& \frac{2 r_{r} L_{m}\left(k_{i \psi}+k_{p \psi} s\right)}{\left(L_{m}+L_{r}\right) s^{2}+\left(r_{r}+2 k_{p \psi} r_{r} L_{m}\right) s+2 k_{i \psi} r_{r} L_{m}}
\end{aligned}
$$

By identification with the canonical form:

$$
\frac{1}{\omega_{n}^{2}} s^{2}+\frac{2 \zeta}{\omega_{n}} s+1
$$

$$
k_{p \psi}=\frac{2 \zeta \omega_{n}\left(L_{m}+L_{r}\right)-r_{r}}{r_{r} L_{m}}
$$

$$
k_{i \psi}=\omega_{n}^{2} \frac{L_{m}+L_{r}}{2 r_{r} L_{m}}
$$


We choose the coefficient for $\zeta=0.7, \omega_{n}=\frac{3}{t_{r}}$ and $t_{r}=(0.5) 10^{-1} s$.

\section{The fuzzy logic controller}

The main feature of the fuzzy logic controllers (initiated by Mamdani and Assilian based on Fuzzy set theory suggested by Zadeh in 1965) is that linguistic, imprecise knowledge of human experts is used [31].

The proposed voltage fuzzy PI controller block diagram is shown in Fig. 8, it has two inputs and one output.

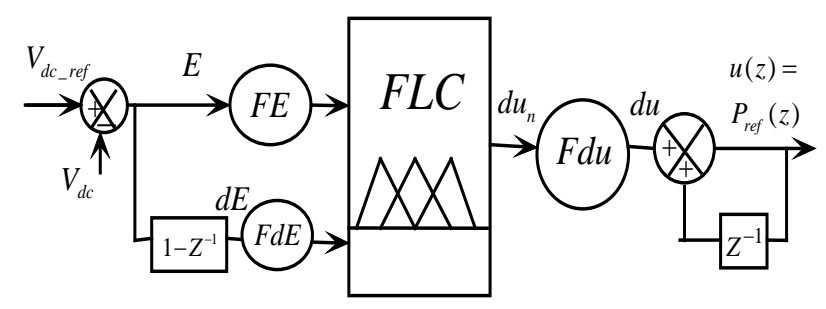

Figure 8. Structure of the fuzzy PI controller

Where $E$ is the error, expressed by:

$$
E(k)=V_{D C}^{*}(k)-V_{D C}(k-1)
$$

$d E$ is derived from the error approximated by:

$$
d E(k)=E(k)-E(k-1)
$$

The output of the regulator is given by:

$$
P^{*}(k)=P^{*}(k-1)-d U(k)
$$

$F E, F d E, F d U$ are gains called "scale factor" they can change the sensitivity of the controller without changing its structure.

The PI transfer function connecting the error $E$ to the control reference signal $\mathrm{u}$ expressed in $\mathrm{Z}$ is:

$$
\frac{V_{D C}^{*}(z)}{E(z)}=k_{p}+k_{i} \frac{z}{z-1}
$$

Where: $k_{p}$ and $k_{i}$, are the gains of the PI controller. From Eq. 44. We obtain the following equation:

$$
u(z)\left(1-z^{-1}\right)=k_{p}\left(1-z^{-1}\right) E(z)+k_{i} E(z)
$$

If we note respectively $d E$ the change of the error $E$ and du the change of the signal control $u$ then Eq. 44. becomes:

$$
d u=k_{p} d E(z)+k_{i} E(z)
$$

The output of the regulator PI controller is according to the error $E$ and of its change $d E$. Then, it appears completely natural to preserve the same inputs and outputs for the fuzzy controller equivalent.

These parameters are adjusted in real time according to the disturbance which increases. It is a question of associating the fuzzy regulator output to the proportional and integral actions of the control signal.

The fuzzy controller is composed of three blocks:

- Fuzzification,

- Rules bases,

- Defuzzification.

\subsection{Fuzzification}

The crisp input variables are $E(k)$ and $d E(K)$ are transformed into Fuzzy variables referred to as linguistic labels. The membership functions associated with each label have been chosen with triangular shapes [32-33].

The universe of discourse of all input and output variables are established as $(-1,1)$. The suitable scaling factors are chosen to bring the input and output variables to this universe of discourse.

Figure 9. Shows the function of membership of each input signals $(E, d E)$. Each universe of discourse is divided into seven overlapping fuzzy sets: PB (Positive Big), PM (Positive Medium), PS (Positive Small), ZE (Zero Environ), NS (Negative Small), NM (Negative Medium), and NB (Negative Big). Each fuzzy variable is a member of the subsets with a degree of membership $\mu$ varying between 0 (nonmember) and 1 (full-member). 


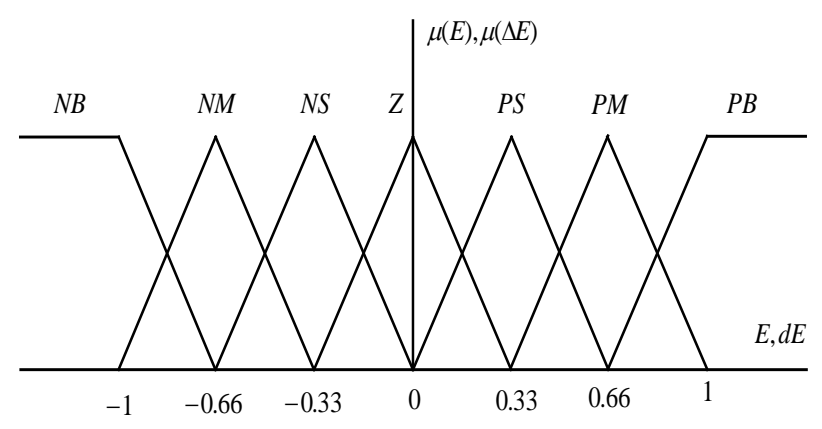

\subsection{Rules bases}

Fuzzy logic rule database consists of series if-andthen fuzzy logic condition sentences. Table 1 shows the corresponding rule table for the fuzzy controller, the design of these rules is based on a qualitative knowledge, deduced from extensive simulation tests [34]. There are 7 fuzzy subsets for each variable, which gives $7 * 7=49$ possible rules.

Figure 9. Membership functions

Table 1. Rules bases

\begin{tabular}{|c|c|c|c|c|c|c|c|}
\hline $\mathrm{dE}, \mathrm{dU}$ & $\mathrm{PB}$ & $\mathrm{PM}$ & $\mathrm{PS}$ & $\mathrm{Z}$ & NS & NM & NB \\
\hline PB & NB & NB & NB & NB & NM & NS & Z \\
\hline PM & NB & NB & NB & NM & NS & Z & PS \\
\hline PS & NB & NB & NS & NS & Z & PS & PM \\
\hline Z & NB & NM & NS & Z & PS & PM & PB \\
\hline NS & NM & NS & Z & PS & PS & PB & PB \\
\hline NM & NS & Z & PS & PM & PB & PB & PB \\
\hline NB & Z & PS & PM & PB & PB & PB & PB \\
\hline
\end{tabular}

\subsection{Deffuzification}

In this step, the fuzzy variables are converted into

$$
I A E=\int_{0}^{\infty}|e(t)| \cdot d t
$$

the crisp variable. In this paper, the center of gravity defuzzification method is adopted here and the inference strategy used in this system is the Mamdani algorithm [34-35]. The output function is given as:

$$
\begin{aligned}
& I S E=\int_{0}^{\infty}\{e(t)\}^{2} \cdot d t \\
& I T A E=\int_{0}^{\infty} t|e(t)| \cdot d t
\end{aligned}
$$

$$
u_{f}=\frac{\sum_{k=1}^{n} u_{f(k)} \mu\left(u_{f(k)}\right)}{\sum_{k=1}^{n} \mu\left(u_{f(k)}\right)}
$$

Where $\mathrm{n}$ is the total number of rules and $\mu\left(u_{f(k)}\right)$ denotes the output membership value for $k^{\text {th }}$ rule.

\section{Selection of performance parameters}

The criterion used to measure the quality of system response must take into account the variation in error over the whole range of time. The four basic criteria are commonly used: Integral of absolute error (IAE), Integral of squared error (ISE), and Integral of time multiplied by absolute error (ITAE) [36]. These parameters are evaluated as follows:

\section{Interpretation of the results}

The simulation of the proposed control scheme has been implemented using Matlab/Simulink. The sample time used $T_{s}=50 \mu \mathrm{s}$.

Figure 10 shows the DC bus voltage. The reference of the DC bus voltage is set at $1100 \mathrm{~V}$. According to this figure the DC bus voltage is mainly controlled to its reference with the proposed control technique but the DC bus voltage cannot follow the DC bus reference when the rotor speed changes to the low value. It is clear from Fig. 10 that the conventional control scheme is not suitable to achieve the desired DC voltage and not robust under high variations of rotor speed and load.

For a good performance of the DC voltage control, the PI controller is replaced by a fuzzy controller. 
To compare the PI and fuzzy PI controllers the DC bus voltage given in Fig. 10, its shown that the fuzzy PI controller is better than the conventional PI controller and the DC bus voltage is mainly controller with the fuzzy PI controller.

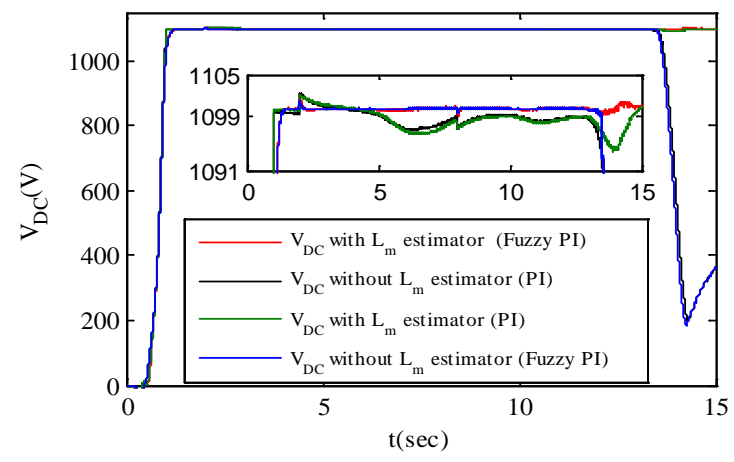

Figure 10. DC link voltage and zoom of DC link voltage

Simulation results show that the PI DC voltage controller suffers from overshoot and takes more settling time to reach the steady state. The fuzzy PI controller responded with lesser overshoot and took less time to reach the steady-state value compared to conventional PI.

The fuzzy PI controller shows a better performance $\left(\mathrm{IAE}=821.7, \mathrm{ISE}=7.65 .10^{5}\right.$, ITAE=392.7) and the peak overshoot $0.2 \%$ during all time as compared with its conventional counterpart PI (IAE=877.3, ISE $=7.66 .10^{5}$, ITAE $=400$ ) the peak overshoot $0.54 \%$ during all time.

During the simulation, the system has been exposed to a speed and load variation to see the response of the control. These variations can be seen in Fig. 11. It is evident that the neglecting the estimation of magnetizing inductance in vector control can result in a detuned operation. This effect is clearly shown in Fig. 12 and Fig. 13.

Figure 14 represents stator voltage and current for star 1 and 2, the second star is shifted by an electrical angle $\alpha=30^{\circ}$ from the first star.

In Fig. 15, the stator phase current is shown to be successfully maintained within the imposed hysteresis band limits for different load values, where the fixed current band ' $h$ ' is set to $0.5 \mathrm{~A}$.

Figure 16 shows that the rotor flux $\psi_{r}$ is constant during entire operation with the proposed control. But with the conventional control, the rotor flux cannot follow its reference when the rotor speed change to low value.

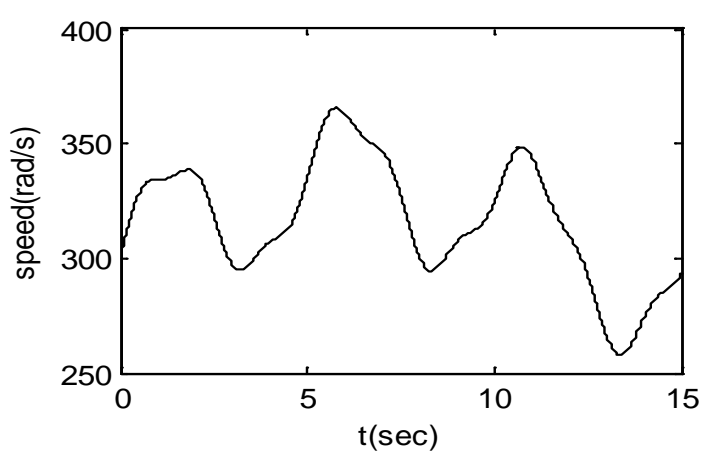

a)

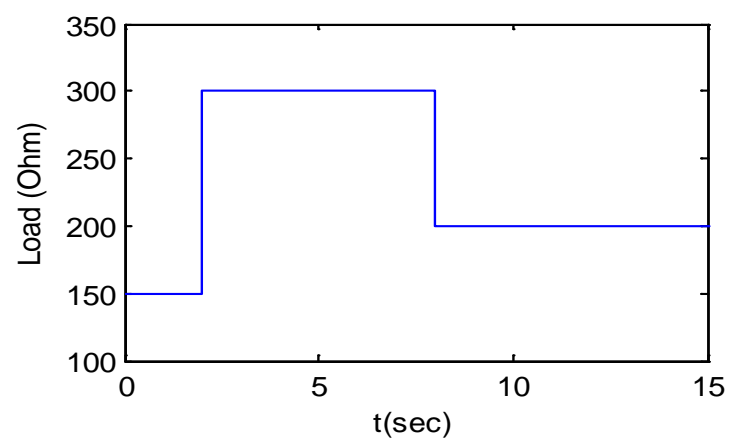

b)

Figure 11. a) Rotor speed and b) Load

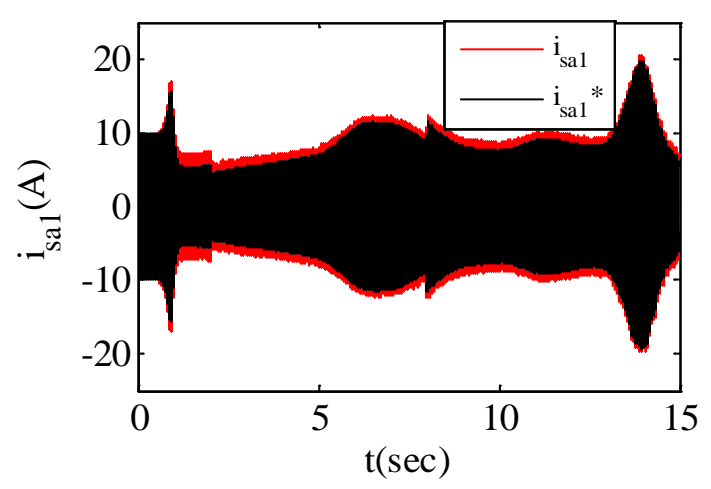

a)

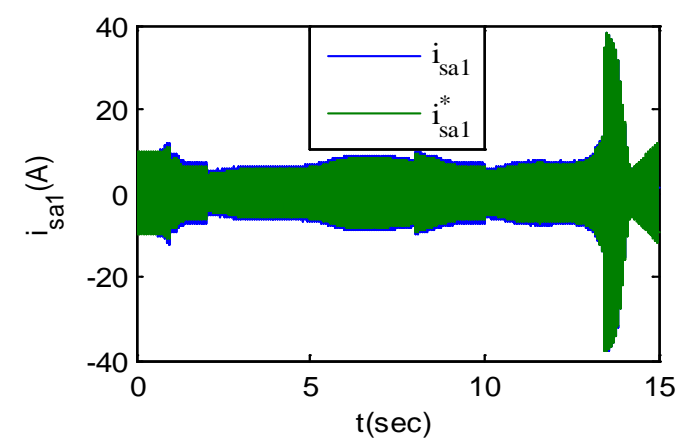

b)

Figure 12. Stator current a) with proposed control b) with conventional control 


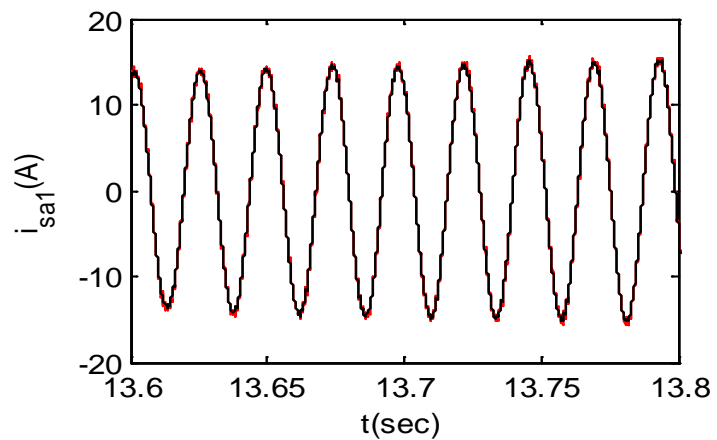

a)

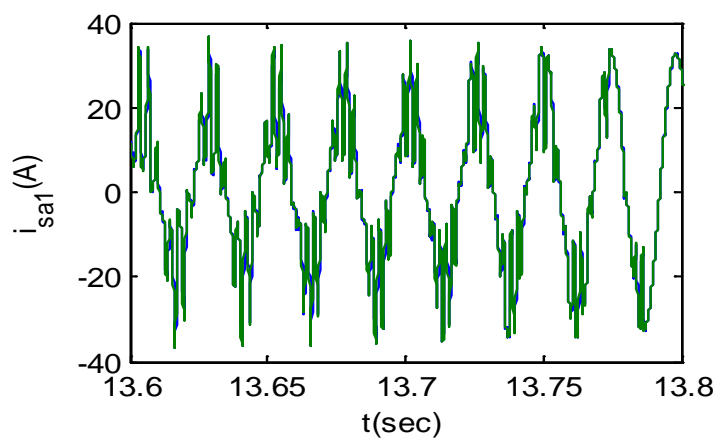

b)

Figure 13. Steady-state current - detuning effect (a) proposed control and (b) conventional control system

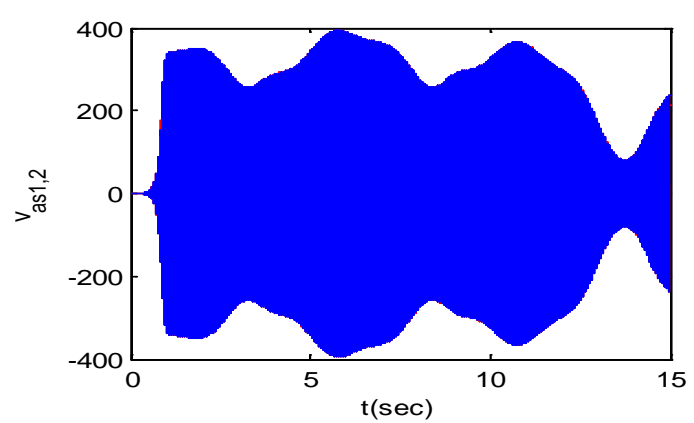

a)

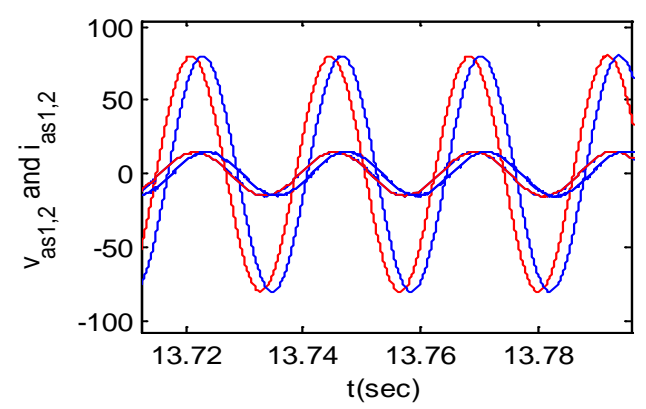

b)

Figure 14. a). Stator voltage and current for star 1 and $2, b$ ). zoom of stator voltage and current for star 1 and 2

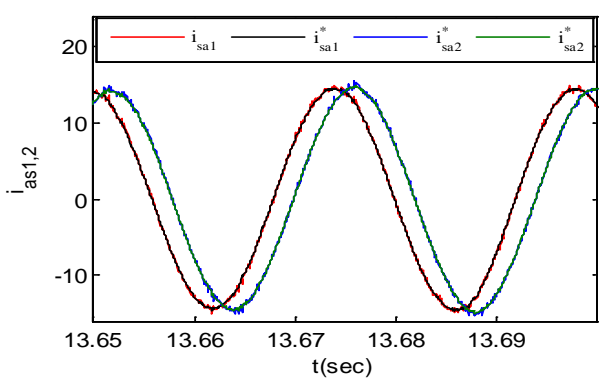

Figure 15. Stator current for star $(1,2)$ and its references

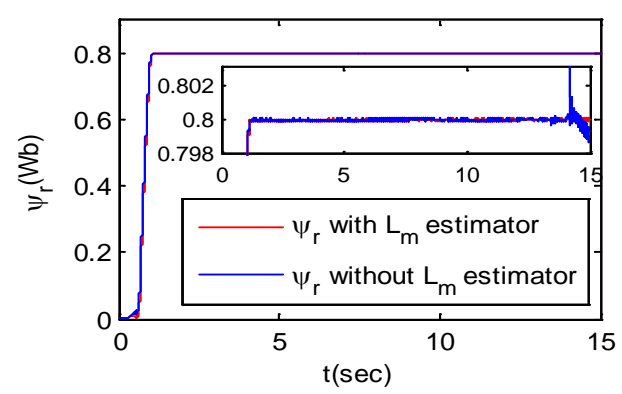

Figure 16. Rotor flux

The real magnetizing inductance, as well as the estimated one, are presented in Fig. 17(b) where the error between the real and the estimated one is lower than 0.01 of its value.

Figure 17 shows the magnetizing current and magnetizing inductance within the estimator.

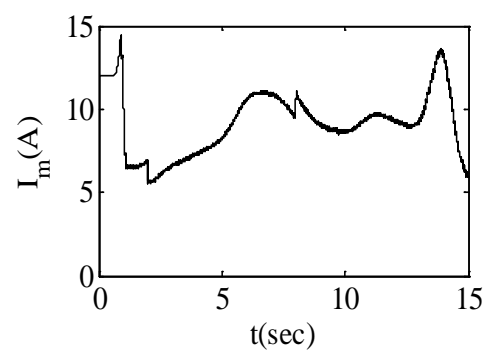

a)

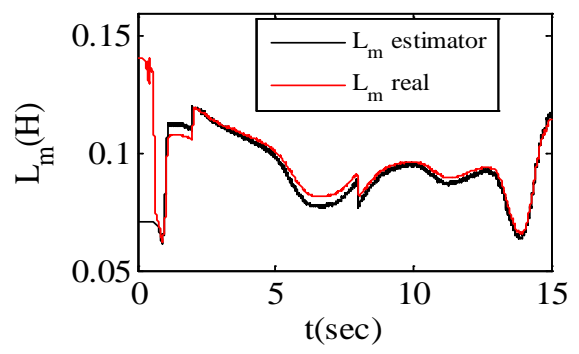

b)

Figure 17. a) Magnetizing current, b) magnetizing inductance 


\section{Conclusion}

In this paper, a rotor flux oriented control using fuzzy logic applied to self-excited dual star induction generator, in a variable speed wind system, have been presented and studied.

Neglecting estimation of magnetizing inductance in vector control of the dual star induction generator can lead to detuned steady state operation.

The proposed control provides good DC voltage control with near sinusoidal stator current and low harmonic.

Further research and experimentation must be carried out in order to validate the results obtained.

\section{Appendix A. DSIG parameters}

\begin{tabular}{|l|l|}
\hline$r_{1,2}$ & $1.9 \Omega$ \\
\hline$r_{r}$ & $2.9 \Omega$ \\
\hline$L_{l 1,2}$ & $0.0132 \mathrm{H}$ \\
\hline$L_{l r}$ & $0.0132 \mathrm{H}$ \\
\hline$L_{m}$ & $0.011 \mathrm{H}$ \\
\hline $2 \mathrm{p}$ & 4 \\
\hline
\end{tabular}

\section{Appendix B. PI and Fuzzy PI parameters}

\begin{tabular}{|l|l|}
\hline$K_{i D C}$ & 1.98 \\
\hline$K_{p D C}$ & 0.0924 \\
\hline$K_{i \psi}$ & 8534.48 \\
\hline$K_{p \psi}$ & 68.4 \\
\hline FE & 1.25 \\
\hline FdE & $9.09 \mathrm{e}-4$ \\
\hline FdU & 0.8 \\
\hline
\end{tabular}

\section{Appendix C. Nomenclature}

\begin{tabular}{|l|l|}
\hline $\begin{array}{l}v_{d s 1}, \\
v_{q s 1}, v_{d s 2}, v_{q s 2}\end{array}$ & “d-q” stator voltages \\
\hline$i_{d s 1}, i_{q s 1}, i_{d s 2}, i_{q s 2}$ & “d-q” stator currents \\
\hline$\psi_{d s 1}, \psi_{q s 1}, \psi_{d s 2}$ & “d-q” stator flux \\
$\psi_{q s 2}$ & \\
\hline$v_{d r}, v_{q r}$ & “d-q” rotor voltages \\
\hline$i_{d r}, i_{q r}$ & “d-q” rotor currents \\
\hline
\end{tabular}

\begin{tabular}{|l|l|}
\hline$\psi_{d r}, \psi_{q r}$ & “d-q" rotor flux \\
\hline$r_{1}, r_{2}$ & Per phase stator resistances \\
\hline$r_{r}$ & Per phase rotor resistance \\
\hline $\begin{array}{l}L_{s 1 d}, L_{s 1 q}, L_{s 2 d}, \\
L_{s 2 q}\end{array}$ & “d-q" stator inductances \\
\hline$L_{r d}, L_{r q}$ & “d-q" rotor inductances \\
\hline$L_{m}$ & Magnetizing inductance \\
\hline$i_{m}$ & Magnetizing current \\
\hline $\mathrm{p}$ & Number of pair pole \\
\hline$T_{e m}$ & Electromagnetic torque \\
\hline$P_{e l e}$ & Electromagnetic power \\
\hline$\omega_{e}$ & $\begin{array}{l}\text { Speed of the synchronous } \\
\text { reference frame }\end{array}$ \\
\hline$\omega_{r}$ & $\begin{array}{l}\text { Rotor electrical angular } \\
\text { speed }\end{array}$ \\
\hline
\end{tabular}

\section{References}

[1] Umesh, B. S, Sivakumar, K.: Multilevel Inverter Scheme for Performance Improvement of Pole Phase Modulated Multiphase Induction Motor Drive, IEEE Transactions on Industrial Electronics, 63 (2015), 2036 - 2043.

[2] Elkheir, M., Hocine, A., Farid, H., Rachid, A.: Self-tuning fuzzy logic controller for a dual star induction machine, JEET, Vol (2011), 1, 133138.

[3] Singh, G. K.: Multi-phase induction drive research - a survey (periodical style), Electric Power Systems Research, 61 (2002), 139-147.

[4] Levi, E.: Multiphase electric machines for variable speed applications, IEEE Transactions on Industrial Electronics, 55 (2008), 18931909.

[5] Abdel-Khalik, A. S., Masoud, M. I., Williams, B. W.: Vector controlled multiphase induction machine: Harmonic injection using optimized constant gains, Electric Power Systems Research, 89 (2012), 116-128.

[6] Salima, L., Tahar, B., Youcef, S.: Indirect rotor field oriented control based on fuzzy logic controlled double star induction machine, Electric Power and Energy Systems, 57 (2014), 206-211.

[7] Federico, B., Mario, J. D.: Recent Advances in the Design, Modeling and Control of Multiphase Machines - Part 1, IEEE 
Transactions on Industrial Electronics, 63 (2016), 1, 449-458.

[8] Mario, J. D., Federico, B.: Recent Advances in the Design, Modeling and Control of Multiphase Machines - Part 2, IEEE Transactions on Industrial Electronics, 63 (2016), 1, 459-468.

[9] Levi, E.: Advances in Converter Control and Innovative Exploitation of Additional Degrees of Freedom for Multiphase Machines, IEEE Transactions on Industrial Electronics, 63 (2016), 1, 433-448.

[10] Levi, E., Federico, B., Mario, J. D.: Multiphase Machines and Drives - Revisited, IEEE Transactions on Industrial Electronics, 63 (2016), 1, 429-432.

[11] Rinkeviciene, R., Kundrotas, B., Lisauskas, S.: Model of Controlled Six phase Induction Motor, International Journal of Electrical and Computer Engineering, 7 (2013), 1, 8-12.

[12] Grogor, R., Barrero, F., Toral, S., Duran, M. J.: Realization of an asynchronous six-phase induction motor drive test-rig, in Proc. International Conf. Renewable Energy and Power Quality, 2008.

[13] Li, Y., Huang, W., Liu, L., Zhang, Y.: The capacity optimization for the static excitation controller of the dual stator winding induction generator operating in a wide speed range, IEEE Transactions on Industrial Electronics, 56 (2009), 2, 530-541.

[14] Bu, F., Hu, Y., Huang, W., Zhang, S., Shi, K.: Control strategy and dynamic performance of dual stator winding induction generator variable frequency ac generating system with inductive and capacitive loads, IEEE Transactions on Industrial Electronics, 29 (2014), 4, 1681-1692.

[15] Basak, S., Chakraborty, C.: Dual stator winding induction machine: problems, progress, and future scope, IEEE Transactions on Industrial Electronics, 62 (2015), 7, 46414652.

[16] Tir, Z., Malik, O.P., Eltamaly, A.M.: Fuzzy logic based speed control of indirect rotor field oriented controlled double star induction motors connected in parallel to a single sixphase inverter supply, Electric Power Systems Research, 134 (2016), 126-133.

[17] Kundrotas, B., Lisauskas, S. Rinkeviciene, R.: Model of Multiphase Induction Motor, Eelektronika ir Elektrotechnika, 5 (2011).
[18] Božo, T., Marin, D., Alojz, S.: Magnetization Curve Identification of Vector-Controlled Induction Motor at Low-Load Conditions, Automatika, 53 (2012), 3.

[19] Idjdarene, K., Rekioua, D., Rekioua, T., Tounzi, A.: Vector control of autonomous induction generator taking saturation effect into account, Energy Conversion and Management, 49 (2008), 2609-2617.

[20] Margato, E., Faria, J., Resende, M. J., Palma, J.: A new control strategy with saturation effect compensation for an autonomous induction generator driven by wides range turbines, Energy Conversion and Management, 5 (2011), 2142-2152.

[21] Lin, F. J., Huang, P. K., Wang, C. C., Teng, L. T.: An induction generator system using fuzzy modeling and recurrent fuzzy neural network, IEEE Transactions on Power Electronics, 22 (2007), 260-271.

[22] Bašić, M., Vukadinović, D.: Online Efficiency Optimization of a Vector Controlled Self Excited Induction Generator, IEEE Transactions on Energy Conversion, 31 (2016), 1.

[23] Bašić, M., Vukadinović, D.: Vector control system of a self-excited induction generator including iron losses and magnetic saturation, Control Engineering Practice, 21 (2013) 395406.

[24] Hazra, S., Sensarma, P.: Self-excitation and control of an induction generator in a standalone wind energy conversion system. Renewable Power Generation, IET. 4. 383 393. 10.1049/iet-rpg.2008.0102, 2010.

[25] Samira, C., Narimen, A. L., Djamal, A., Kaci, G.: Fuzzy logic control strategy of wind generator based on the dual-stator induction generator, Electrical Power and Energy Systems, 59 (2014), 166-175.

[26] Singh, G.K.: Modeling and experimental analysis of a self-excited six-phase induction generator for stand-alone renewable energy generation, Renewable Energy, 33 (2008), 1605-1621.

[27] Amimeur, H., Aouzellag, D., Abdessemed, R., Ghedamsi, K.: Sliding mode control of a dual stator induction generator for wind energy conversion systems, Electrical Power and Energy systems, 2012, 42, 60-7.

[28] Zhiquiao, W., Olorunfemi, O., Jyoti, S.: Highperformance control of a dual stator winding 
DC power induction generator, IEEE Trans. Ind. Appl., 43 (2009), 2, march/april 2007.

[29] Chinmay, K.A., Singh, G.: Performance evaluation of multiphase induction generator in stand-alone and grid-connected wind energy conversion system, IET Renewable Power Generation. 10.1049/iet-rpg.2017.0791, 2017.

[30] Singh, G.K., Yadav, K.B., Saini, R.P.: Modeling and analysis of multi-phase (sixphase) self-excited induction generator. ICEMS 2005: Proceedings of the Eighth International Conference on Electrical Machines and Systems, 3, 1922 - 1927.

[31] Zadeh, L. A.: Fuzzy sets, Information and Control, 8 (1965), 338-353.

[32] José, L., Azcue, P., Alfeu, J., Sguarezi F., Ernesto, R.: Self-Tuning PI-Type Fuzzy Direct Torque Control for Three-phase Induction Motor, WSEAS Transactions on Circuits and Systems, 11 (2012), 10, 319-328.
[33] Min, Z., Xi, C., Dihua, S.: An incident detection method considering meteorological factor with fuzzy logic, Engineering Review, 38 (2016), 1, 104-114.

[34] Mamdani, E., Assilion, S., Jabr, H.: An experiment in Linguistic Synthesis With a Fuzzy Logic Controller, Int. J. Man Machine Stud., 7 (1974), 1-13.

[35] Sousa, G. C. D., Bose, B. K.: A Fuzzy set theory based control of a phase controlled converter DC machine drive, IEEE Trans. on Ind. Applicat., 30 (1994), 1, 1-13.

[36] Ansari, A. Q., Ibraheem, N., Katiyar, S.: Application of ant colony algorithm for calculation and analysis of performance indices for adaptive control system, 2014 Innovative Application of Computational Intelligence on Power, Energy and Controls with their Impact on Humanity (CIPECH), Ghaziadab, India 2014. 